\title{
Effect of the Association of Nonsteroidal Anti-inflammatory and Antibiotic Drugs on Antibiofilm Activity and $\mathrm{pH}$ of Calcium Hydroxide Pastes
}

\author{
Rafaela Pignatti de Freitas, DDS, ${ }^{*}$ Vanessa Raquel Greatti, MSc, ${ }^{\dagger}$ Murilo Priori Alcalde, MSc, \\ Bruno Cavalini Cavenago, PbD, ${ }^{\complement}$ Rodrigo Ricci Vivan, PbD, ${ }^{\neq}$ \\ Marco Antonio Hungaro Duarte, PbD, ${ }^{\neq}$Ana Carolina Villas Bôas Weckwerth, DDS," \\ and Paulo Henrique Weckwerth, $P b D^{*}$
}

\begin{abstract}
Ahstract
Introduction: The objective of the present study was to evaluate the in vitro antibiofilm activity and $\mathrm{pH}$ of calcium hydroxide associated with different nonsteroidal anti-inflammatory drugs (NSAIDs). Methods: The groups analyzed were as follows: group 1, calcium hydroxide paste with propylene glycol; group 2 , calcium hydroxide paste with propylene glycol + $5 \%$ diclofenac sodium; group 3, calcium hydroxide paste with propylene glycol $+5 \%$ ibuprofen; group 4 , calcium hydroxide paste with propylene glycol + $5 \%$ ciprofloxacin; and group 6, positive control (without medication). For analysis of the $\mathrm{pH}$, the pastes were inserted into tubes and immersed in flasks containing ultrapure water. At the time intervals of $3,24,72$, and 168 hours, the $\mathrm{pH}$ was measured with a calibrated $\mathrm{pH}$ meter. For microbial analysis, biofilm was induced in 30 bovine dentin blocks for 21 days. Subsequently, the pastes were placed on the blocks with biofilm for 7 days. Afterward, the pastes were removed by irrigation with sterile water, and the specimens were analyzed with a laser scanning confocal microscope with the $50 \mu \mathrm{L}$ Live/Dead BacLight Bacterial Viability solution L7012 Kit (Molecular Probes, Inc, Eugene, OR). Data were subjected to statistical analysis at a significance level of $5 \%$. Results: The highest $\mathrm{pH}$ values were found for calcium hydroxide associated with ciprofloxacin in all periods analyzed. With the exception of pure calcium hydroxide paste, the other groups showed statistically significant differences $(P<.05)$ in comparison with the positive control. Conclusions: The association of NSAIDs or antibiotic did not interfere with the $\mathrm{pH}$ of
\end{abstract}

calcium hydroxide paste and increased the antimicrobial action of calcium hydroxide paste against Enterococcus faecalis biofilm formation. (J Endod 2017;43:131134)

\section{Key Words}

Antibiofilm action, calcium hydroxide, diclofenac, ibuprofen, intracanal medication

Calcium hydroxide is widely used in dentistry because of its antimicrobial and biologic effects (1). When used as an intracanal dressing, a vehicle is added to provide paste consistency. Different vehicles have been proposed as additives to calcium hydroxide (2). The dissociation of calcium hydroxide particles allows hydroxyl and calcium ion diffusion from the root canal walls through the dentinal tubules (3).

Calcium hydroxide acts by stimulating tissue mineralization (4), and its biologic and antiseptic effects rely on alkalinity and calcium ion release (3). The high $\mathrm{pH}$ of calcium hydroxide promotes microbial inhibition through an irreversible enzymatic reaction (5). Not only does calcium act by clearing the carbon dioxide used by bacteria for anaerobic respiration (6), but also calcium ions play an essential role in tissue mineralization, stimulating fibronectin gene expression (4). Another important property of calcium hydroxide is its ability to promote inactivation of bacterial lipopolysaccharides found in the outer membrane of gram-negative bacteria (7).

However, persistent infection might occur as a result of the presence of microorganisms that are refractory to endodontic procedures (8). Environmental alterations, such as increases in $\mathrm{pH}$, might stimulate genetic cascades that modify the characteristics of the bacterial cell. Biofilm formation also represents a bacterial adaptation that increases the resistance of the microorganisms (8).

From the *Universidade do Sagrado Coração, Pro-Rectory of Research and Post Graduation, Bauru; ${ }^{\dagger}$ Department of Drugs and Medical, Pharmaceutical Biotechnology Laboratory, School of Pharmaceutical Sciences, São Paulo State University, Araraquara; ${ }^{\ddagger}$ Department of Operative Dentistry, Endodontics and Dental Materials, Bauru School of Dentistry, University of São Paulo, Bauru, Sao Paulo; ${ }^{\S}$ Department of Restorative Dentistry, Federal University of Paraná, Curitiba, Parana; and "Lauro de Souza Lima Institute, Micology Department, Bauru, Sao Paulo, Brazil.

Address requests for reprints to Dr Rodrigo Ricci Vivan, Al Octávio Pinheiro Brisolla, 9-75, Bauru, SP, 17012-901, Brazil. E-mail address: rodrigo.vivan@fob.usp.br 0099-2399/\$ - see front matter

Published by Elsevier Inc, on behalf of American Association of Endodontists.

http://dx.doi.org/10.1016/j.joen.2016.09.014 
Enterococcus faecalis, one of the microorganisms involved in persistent infections (predominantly in endodontic failures) (9), has shown resistance to calcium hydroxide therapy (10). For this reason, the association of calcium hydroxide with other antiseptic agents has been proposed to improve the action against this microorganism.

Several studies (11) have shown that nonsteroidal antiinflammatory drugs (NSAIDs) have proven antimicrobial activity. Diclofenac sodium has a highly bactericidal action against grampositive and gram-negative bacteria by inhibiting the synthesis of bacterial DNA (11). Its antimicrobial effect is potentiated when associated with other drugs (12).

When antimicrobial activity was analyzed by means of radial diffusion assay, the effect of sodium diclofenac, ibuprofen, amoxicillin, and gentamicin, front-line drugs against $E$. faecalis ATCC 29212 (American Type Culture Collection, Rockville, MD), was verified and compared with the results provided by calcium hydroxide paste; a greater effectiveness of NSAIDS and antibiotics was observed in comparison with calcium hydroxide paste (13). In addition to $E$. faecalis, other microorganisms such as Staphylococcus aureus, Listeria monocytogenes, Escherichia coli, and Mycobacterium tuberculosis have shown sensitivity to NSAIDs (14).

Calcium hydroxide paste showed low antibiofilm action (15), and the association of NSAIDs with calcium hydroxide paste has not yet been evaluated. Therefore, the objective of the present study was to analyze the effect of the association of diclofenac sodium, ibuprofen, or ciprofloxacin with calcium hydroxide paste on $\mathrm{pH}$ and antimicrobial action against the biofilm of $E$. faecalis. The null hypotheses tested were that NSAIDS and ciprofloxacin would not interfere with antibiofilm action of calcium hydroxide paste and would not interfere with the $\mathrm{pH}$ of calcium hydroxide paste.

\section{Material and Methods Preparation of Bovine Dentin Specimens}

Thirty sterilized bovine dentin blocks were used. The blocks of bovine incisor teeth were obtained by using an IsoMet metallographic cutting machine (Buehler Ltd, Lake Bluff, IL). Cuts were made until specimens measuring $4 \mathrm{~mm}$ in diameter and 0.8 thickness were obtained.

Afterward, the blocks were fixed in a polishing machine and polished. The dentin segments were treated with $1 \%$ sodium hypochlorite for 30 minutes and 17\% EDTA for 5 minutes to remove organic waste and possible presence of the smear layer. To verify the cleaning method, 3 blocks were observed by scanning electron microscopy. The blocks were sterilized in autoclave at $121^{\circ} \mathrm{C}$.

\section{Contamination of the Dentin}

For inducing the biofilm on the dentin blocks, E. faecalis ATCC 29212 was used according to the methodology recommended by Guerreiro-Tanomaru et al (16). After confirming the purity of the microorganism by Gram stain, morphology of the colony, and biochemical identification, the microorganism was reactivated in $4 \mathrm{~mL}$ sterile brain-heart infusion (BHI) broth and kept in an oven at $37^{\circ} \mathrm{C}$ for 12 hours.

After this, the optical density of the medium was measured and adjusted in a spectrophotometer (Model 600 Plus; Femto, São Paulo, SP, Brazil) with a wavelength of $600 \mathrm{~nm}$. The cell density of $1.5 \times$ $10^{8}$ colony-forming units per milliliter $(\mathrm{cfu} / \mathrm{mL})$ was adjusted. The dentin blocks were placed into two 24-well cell culture plates within an area marked with a pencil, facing down. Then, the blocks were submerged in $3.6 \mathrm{~mL}$ sterile BHI broth with the addition of $0.4 \mathrm{~mL}$ standardized bacterial inoculum. The plates were placed in a bacteriological oven at $37^{\circ} \mathrm{C}$ for 21 days. To avoid nutrient deficiency in the bacterial cells, the BHI culture medium of each specimen was completely replaced every 48 hours, without the addition of new microorganisms.

\section{Antihiofilm Activity Test}

After the biofilm induction period, all blocks were removed from culture broths, rinsed 3 times with sterile buffered saline solution to remove planktonic cells, dried with a sterile needle, and randomly distributed on the surface of sterile Petri dishes according to each tested antibiotic as follows: group 1, calcium hydroxide paste with propylene glycol; group 2, calcium hydroxide paste with propylene glycol $+5 \%$ diclofenac sodium; group 3, calcium hydroxide paste with propylene glycol $+5 \%$ ibuprofen; group 4, calcium hydroxide paste with propylene glycol + 5\% ciprofloxacin; and group 5, positive control (without medication). The powders of substances (NSAIDs and antibiotics) were added to the calcium hydroxide powder at the rate of $5 \%$ by weight. To manipulate the pastes, $1 \mathrm{~g}$ powder was mixed with $1 \mathrm{~mL}$ propylene glycol.

In groups 1 to 4 , the block surfaces were covered with the calcium hydroxide pastes tested $(0.1 \mathrm{~mL})$. In the control group, the block containing biofilm was placed in contact with saline solution. The blocks were incubated again at $37^{\circ} \mathrm{C}$ for 7 days at $100 \%$ humidity produced by sterile cotton soaked with sterile ultrapure water. After this period, the blocks were removed from the incubation chamber; the pastes were removed by irrigation with $2 \mathrm{~mL}$ sterile water, and then the blocks were dried with a sterile needle.

\section{Confocal Microscopic Analysis}

The specimens were placed into Petri dishes and stained with $50 \mu \mathrm{L}$ Live/Dead BacLight Bacterial Viability L7012 solution (Molecular Probes, Inc, Eugene, OR) trickled over the dentin. After the application of dyes, the Petri dishes were closed and wrapped in tinfoil to allow dye diffusion into the specimens, in the absence of light, at a temperature of $37^{\circ} \mathrm{C}$ for 20 minutes according to the manufacturer's guidelines. To prepare the dye Live/Dead BacLight, $1.5 \mu \mathrm{L}$ component A and $1.5 \mu \mathrm{L}$ component $B$ were added to $0.97 \mathrm{~mL} 0.85 \%$ saline solution. The marker colored the viable cells in green and the cells with membrane damage in red.

All specimens were examined under confocal laser scanning microscopy (Leica TCS-SPE; Leica Microsystems GmbH, Mannheim, Germany) at $40 \times$ magnification. Six specimens were photographed in each

TABLE 1. The Mean and Standard Deviation $\mathrm{pH}$ Values of the Calcium Hydroxide (CH) Pastes Tested in the Different Time Intervals

\begin{tabular}{lcccc}
\hline \multicolumn{1}{c}{ Pastes } & $\mathbf{3 h}$ & $\mathbf{2 4} \mathbf{h}$ & $\mathbf{7 2 h}$ & $168 \mathrm{~h}$ \\
\hline $\mathrm{CH}+$ diclofenac & $10.62 \pm 0.14^{\mathrm{aA}}$ & $11.87 \pm 0.08^{\mathrm{aB}}$ & $11.58 \pm 0.21^{\mathrm{aC}}$ & $12.18 \pm 0.14^{\mathrm{aD}}$ \\
$\mathrm{CH}+$ ibuprofen & $11.36 \pm 0.43^{\mathrm{bA}}$ & $11.96 \pm 0.18^{\mathrm{aB}}$ & $12.20 \pm 0.19^{\mathrm{bC}}$ & $12.32 \pm 0.10^{\mathrm{acC}}$ \\
$\mathrm{CH}+$ ciprofloxacin & $11.99 \pm 0.49^{\mathrm{CA}}$ & $12.75 \pm 0.13^{\mathrm{bB}}$ & $12.40 \pm 0.15^{\mathrm{bC}}$ & $12.84 \pm 0.15^{\mathrm{bB}}$ \\
$\mathrm{CH}$ & $11.33 \pm 0.27^{\mathrm{bA}}$ & $11.85 \pm 0.18^{\mathrm{aB}}$ & $12.23 \pm 0.11^{\mathrm{bC}}$ & $12.45 \pm 0.07^{\mathrm{CD}}$ \\
\hline
\end{tabular}

Different lowercase letters show statistically significant differences between $\mathrm{CH}$ pastes in the same period, and different capital letters represent statistically significant differences between periods in a same $\mathrm{CH}$ paste $(P<.05)$. 
TABLE 2. The Median, Minimum, and Maximum Values of the Biovolume $\left(\mathrm{mm}^{3}\right)$ and Percentage of Live Bacteria after Being in Contact with the Calcium Hydroxide (CH) Pastes Tested

\begin{tabular}{|c|c|c|c|c|c|}
\hline & $\mathrm{CH}+$ diclofenac & $\mathrm{CH}+$ ibuprofen & CH + ciprofloxacin & $\mathrm{CH}$ & Control \\
\hline Biovolume & $33.03^{a}(1.88-102.9)$ & $20.12^{a}(1.26-193.56)$ & $23.38^{a}(0.83-156.37)$ & $20.02^{a}(1.94-277)$ & $90.29^{a}(10.65-422.36)$ \\
\hline $\begin{array}{l}\text { Percentage } \\
\text { of live bacteria }\end{array}$ & $19.46^{a}(0.02-71.72)$ & $52.33^{a}(1.87-99.5)$ & $27.02^{a}(0.5-73.83)$ & $55.88^{\mathrm{ab}}(13.46-84.61)$ & $83.37^{b}(63.54-95.14)$ \\
\hline
\end{tabular}

Different lowercase letters show statistically significant differences between $\mathrm{CH}$ pastes and the control in comparison with biovolume and the percentage of live bacteria $(P<.05)$.

group, and 4 images were taken per specimen, totaling 24 pictures per group.

The images were analyzed by bioImage_ $L$ (Chávez de Paz, Farmington, CT) software for structural analysis of biofilm formed on the dentin blocks and the percentage of live cells according to Chávez de Paz (17).

\section{pH Test}

For $\mathrm{pH}$ analysis, the manipulated pastes were handled in the same proportion as that used for the antibiofilm test and inserted into polyethylene tubes with the aid of a syringe and needle. Immediately afterward, the tubes were placed in flasks containing $10 \mathrm{~mL}$ ultrapure water. After the time intervals of 3, 24, 72, and 168 hours, the $\mathrm{pH}$ of the water was measured with a $\mathrm{pH}$ meter that had previously been calibrated in $\mathrm{pH}$ solutions 4, 7, and 14. Flasks containing only water without material were also measured. Ten specimens were analyzed per group.

\section{Statistical Analysis}

Data obtained on antibiofilm analysis and $\mathrm{pH}$ tests were submitted to normality analysis using the Shapiro-Wilk test. Because of the absence of normality of the data on antibiofilm action, the Kruskal-Wallis and Dunn tests were used for global and individual comparisons. The $\mathrm{pH}$ data showed normal distribution, and the analysis of variance and Tukey tests were used for global and individual comparisons. The significance level was $5 \%$.

\section{Results}

Table 1 presents the values of the mean and standard deviation of $\mathrm{pH}$ of the tested calcium hydroxide pastes in the different time intervals and also shows the differences between pastes in the same period (lowercase) and between periods in the same paste (capital letters). All the tested pastes provided $\mathrm{pH}$ values above 10.0 in all periods analyzed. The highest $\mathrm{pH}$ values were found for the calcium hydroxide paste containing ciprofloxacin, and with the exception of the 24-hour time interval, the lowest values were found for the calcium hydroxide paste containing sodium diclofenac.
Table 2 presents the median, minimum, and maximum values of the biovolume and the percentage of live bacteria in the biofilm after contact with the $\mathrm{CH}$ pastes tested. There were no statistically significant differences between the $\mathrm{CH}$ pastes with respect to the biovolume. Regarding the percentage of live bacteria, there were statistically significant differences between the calcium hydroxide pastes containing the NSAIDs and antibiotic and the control $(P<.05)$. In the comparisons between the calcium hydroxide paste and the control and in the comparisons of the calcium hydroxide paste with NSAIDs and calcium hydroxide paste with antibiotic, there were no statistically significant differences $(P>.05)$. Figure 1 shows representative images of the biofilm of each calcium hydroxide paste tested and the control group.

\section{Discussion}

The null hypotheses tested in the present study were rejected because the groups that presented the addition of NSAIDs and ciprofloxacin increased the effectiveness of the antimicrobial action in biofilm and interfered in the $\mathrm{pH}$ of the calcium hydroxide paste.

The methodology used for testing the antimicrobial action of the calcium hydroxide pastes and substances using confocal microscopy with live/dead dye was similar to that used previously (18).

Dissolution of biofilms by dressings is crucial because a significant area of the root canal system is inaccessible to endodontic instruments. The effectiveness of calcium hydroxide against strains of $E$. faecalis and other microorganisms has been widely discussed in the literature (1923).

Frequent recovery of $E$. faecalis in root canals with endodontic treatment failure has been widely reported $(24,25)$. $\boldsymbol{E}$. faecalis has shown high resistance to medications used during treatment and is 1 of the few microorganisms that has been shown to resist the in vitro antibacterial effect of calcium hydroxide $(10,26)$. The resistance of this microorganism to calcium hydroxide is related to the presence of a proton pump (10).

Because of the resistance of $E$. faecalis to calcium hydroxide, substances have been associated with calcium hydroxide paste, such as chlorhexidine (19, 20, 27-29), iodine (27), camphorated
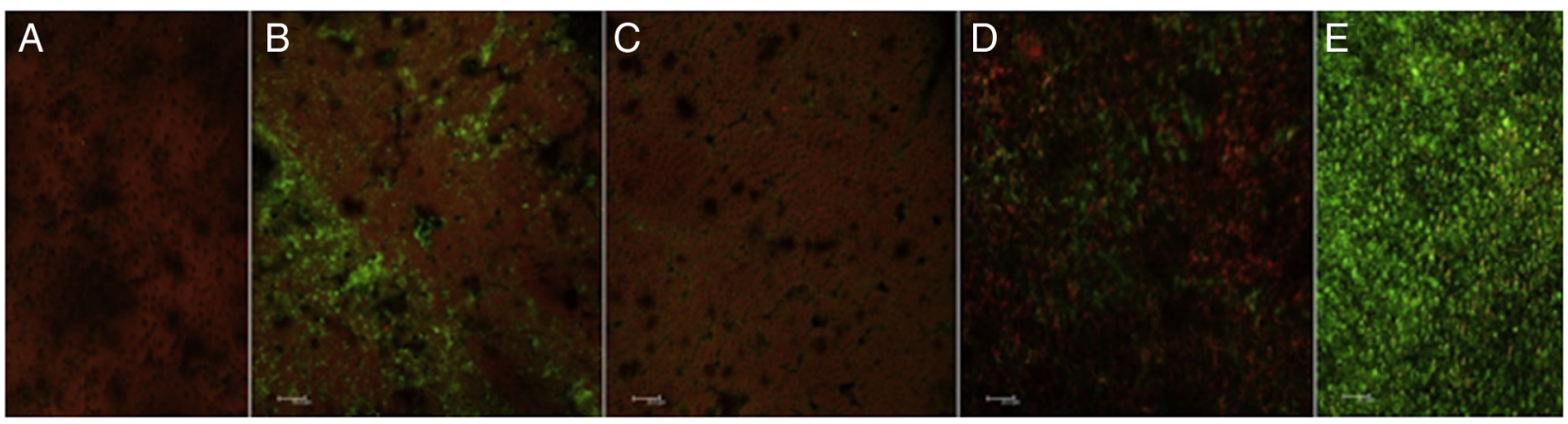

Figure 1. Confocal laser scanning microscopy of biofilms treated with $(A)$ sodium diclofenac, $(B)$ ibuprofen, $(C)$ ciprofloxacin, $(D)$ calcium hydroxide, and $(E)$ control. Live cells are seen in green, and dead cells are seen in red. Each picture represents an area of $275 \times 275 \mu \mathrm{m}$. Bars represent $20 \mu \mathrm{m}$. 
paramonochlorophenol $(29,30)$, iodoform (28), propolis (31), and linezolid (32), in order to enhance the antimicrobial action. Several recent studies have revealed that NSAIDs have proven antimicrobial activity $(11,13,14)$. However, the association of NSAIDs with calcium hydroxide paste and the effect of this association on biofilm had not been tested.

The results showed that calcium hydroxide pastes containing the drugs significantly reduced the percentage of live bacteria in the biofilm, a fact not noted with pure calcium hydroxide pastes; indeed, the results of pure calcium hydroxide paste corroborate the findings of another study (18). In relation to pastes containing drugs, diclofenac reduced the $\mathrm{pH}$ of the paste at the end of 7 days, maintained a more effective antimicrobial action, and showed that the antimicrobial action is not related to the alkalinity of the paste only. Diclofenac sodium has a highly bactericidal action against gram-positive and gram-negative bacteria by inhibiting the synthesis of bacterial DNA (11). The antimicrobial action of sodium diclofenac, ibuprofen, and ciprofloxacin has been shown by the radial diffusion assay (13). Another study using in vivo and in vitro tests proved that the antimicrobial action of diclofenac was increased when associated with another drug (12).

With respect to $\mathrm{pH}$, the association of diclofenac reduced the $\mathrm{pH}$ when compared with the pure paste at the time intervals of 3,72, and 168 hours; however, in all periods, the $\mathrm{pH}$ remained above 10 . Alkalinity is important to antimicrobial and biological action. The alkaline pH favors the activation of alkaline phosphatase, an enzyme that allows the reaction of phosphate with calcium ions from the bloodstream, forming calcium phosphate, which corroborates the biomineralization process (33).

Another important clinical factor in the association of antiinflammatory drugs with calcium hydroxide paste would be a topical action in the control of inflammation, which could reduce postoperative pain in patients after endodontic intervention. However, further studies are necessary to confirm this efficiency. Noting the effectiveness of pure calcium hydroxide paste revealed that its associations with diclofenac sodium, ibuprofen, and ciprofloxacin strengthened the antimicrobial action, with the best performance being observed in association with diclofenac sodium.

\section{Conclusion}

The authors concluded that the association of NSAIDs or antibiotic did not interfere with the $\mathrm{pH}$ of calcium hydroxide paste and increased the antimicrobial action of calcium hydroxide paste against the biofilm of $E$. faecalis.

\section{Acknowledgments}

The authors deny any conflicts of interest related to this study.

\section{References}

1. Desai S, Chandler N. Calcium hydroxide-based root canal sealers: a review. J Endod 2009:35:475-80.

2. Gomes BP, Ferraz CC, Garrido FD, et al. Microbial susceptibility to calcium hydroxide pastes and their vehicles. J Endod 2002;28:758-61.

3. Estrela C, Pimenta FC, Ito IY, et al. In vitro determination of direct antimicrobial effect of calcium hydroxide. J Endod 1998;24:15-7.

4. Mizuno M, Banzai Y. Calcium ion release from calcium hydroxide stimulated fibronectin gene expression in dental pulp cells and the differentiation of dental pulp cells to mineralized tissue forming cells by fibronectin. Int Endod J 2008;41:933-8.

5. Siqueira JF, Lopes HP. Mechanisms of antimicrobial activity of calcium hydroxide: a critical review. Int Endod J 1999:32:361-9.

6. Kontakiotis E, Nakou M, Georgopoulou M. In vitro study of the indirect action of calcium hydroxide on the anaerobic flora of the root canal. Int Endod J 1995; 28:285-9.
7. Tanomaru JM, Leonardo MR, Tanomaru Filho M, et al. Effect of different irrigation solutions and calcium hydroxide on bacterial LPS. Int Endod J 2003;36: 733-9.

8. Siqueira JF, Rôças IN. Clinical implications and microbiology of bacterial persistence after treatment procedures. J Endod 2008;34:1291-301.

9. Pinheiro ET, Gomes BP, Ferraz CCR, et al. Microorganisms from canals of root-filled teeth with periapical lesions. Int Endod J 2003;36:1-11.

10. Evans M, Davies JK, Sundqvist G, et al. Mechanisms involved in the resistance of Enterococcus faecalis to calcium hydroxide. Int Endod J 2002;35:221-8.

11. Dastidar SG, Ganguly K, Chaudhuri K, et al. The anti-bacterial action of diclofenac shown by inhibition of DNA synthesis. Int J Antimicrob Agents 2000;14: 249-51.

12. Dutta NK, Annadurai S, Mazumdar K, et al. Potential management of resistant microbial infections with a novel non-antibiotic: the anti-inflammatory drug diclofenac sodium. Int J Antimicrob Agents 2007;30:242-9.

13. Salem-Milani A, Balaei-Gajan E, Rahimi S, et al. Antibacterial effect of diclofenac sodium on Enterococcus faecalis. J Dent (Tehran) 2013;10:16-22.

14. Mazumdar K, Dastidar SG, Park JH, et al. The anti-inflammatory non-antibiotic helper compound diclofenac: an antibacterial drug target. Eur J Clin Microbiol Infect Dis 2009;28:881-91.

15. Ordinola-Zapata R, Bramante CM, de Moraes IG, et al. Confocal laser scanning microscopy is appropriate to detect viability of Enterococcus faecalis in infected dentin. J Endod 2008;34:1198-201.

16. Guerreiro-Tanomaru JM, de Faria-Júnior NB, Duarte MA, et al. Comparative analysis of Enterococcus faecalis biofilm formation on different substrates. Basic Res Biol 2013;39:346-50.

17. Chávez de Paz LE. Image analysis software based on color segmentation for characterization of viability and physiological activity of biofilms. Appl Environ Microbiol 2009;75:1734-9.

18. Ordinola-Zapata R, Bramante CM, Cavenago B, et al. Antimicrobial effect of endodontic solutions used as final irrigants on a dentine biofilm model. Int Endod J 2012;45:162-8.

19. Schäfer E, Bössmann K. Antimicrobial efficacy of chlorhexidine and two calcium hydroxide formulations against Enterococcus faecalis. J Endod 2004; 31:53-6.

20. Ercan E, Dalli M, Dülgergil ÇT. In vitro assessment of the effectiveness of chlorhexidine gel and calcium hydroxide paste with chlorhexidine against Enterococcus faecalis and Candida albicans. Oral Surg Oral Med Oral Pathol Oral Radiol Endod 2006;102:27-31.

21. Evans MD, Baumgartner JC, Khemaleelakul SU, et al. Efficacy of calcium hydroxide: chlorhexidine paste as an intracanal medication in bovine dentin. J Endod 2003;29: 338-9.

22. Gomes BP, Ferraz CCR, Vianna ME, et al. In vitro antimicrobial activity of calcium hydroxide pastes and their vehicles against selected microorganisms. Braz Dent J 2002;13:155-61.

23. Cwikla SJ, Bélanger M, Giguère $S$, et al. Dentinal tubule disinfection using three calcium hydroxide formulations. J. Endod 2004;31:50-2.

24. Sundqvist G, Figdor D, Persson S, et al. Microbiologic analysis of teeth with failed endodontic treatment and the outcome of conservative re-treatment. Oral Surg Oral Med Oral Pathol Oral Radiol Endod 1998;85:86-93.

25. Rôças IN, Siqueira JF, Santos KR. Association of Enterococcus faecalis with different forms of periradicular diseases. J Endod 2004;30:315-20.

26. Weiger R, Manncke B, Werner H, et al. Microbial flora of sinus tracts and root canals of non-vital teeth. Endod Dent Traumatol 1995;11:15-9.

27. Sirén EK, Haapasalo MP, Waltimo TM, et al. In vitro antibacterial effect of calcium hydroxide combined with chlorhexidine or iodine potassium iodide on Enterococcus faecalis. Eur J Oral Sci 2004;112:326-31.

28. Souza-Filho FJD, Soares Ade J, Vianna ME, et al. Antimicrobial effect and $\mathrm{pH}$ of chlorhexidine gel and calcium hydroxide alone and associated with other materials. Braz Dent J 2008;19:28-33.

29. Silveira CF, Cunha RS, Fontana CE, et al. Assessment of the antibacterial activity of calcium hydroxide combined with chlorhexidine paste and other intracanal medications against bacterial pathogens. Eur J Dent 2011;5:1-7.

30. Vianna ME, Gomes BP, Sena NT, et al. In vitro evaluation of the susceptibility of endodontic pathogens to calcium hydroxide combined with different vehicles. Braz Dent J 2005;16:175-80.

31. Rezende GP, Costa LR, Pimenta FC, et al. In vitro antimicrobial activity of endodontic pastes with propolis extracts and calcium hydroxide: a preliminary study. Braz Dent J 2008;19:301-5.

32. Pavaskar R, de Ataide IDN, Chalakkal $\mathrm{P}$, et al. An in vitro study comparing the intracanal effectiveness of calcium hydroxide - and linezolid-based medicaments against Enterococcus faecalis. J Endod 2012;38:95-100.

33. Estrela C, Pécora JD, Souza-Neto MD, et al. Effect of vehicle on antimicrobial properties of calcium hydroxide. Braz Dent J 1999;10:63-72. 